\title{
UNEP/UNESCO Postgraduate Training Course for Developing Countries
}

This year for the eleventh time, the UNEP/UNESCO International Course in Ecological Approaches to Resources Development, Land Management, and Impact Assessment, in Developing Countries is being given at the Technical University of Dresden, German Democratic Republic. The Course is a result of the second phase of an ongoing project which is being run by UNEP, UNESCO, and the Government of East Germany through the Centre for Protection and Improvement of the Environment (CPIE) of the Ministry of Environmental Protection and Water Management, coordinated by Professor Dr E. Seidel. Since its establishment in 1977, this Course has been followed by about 170 professionals in different fields from Africa, Asia, and Latin America. They came from a total of 51 of the less-developed nations, including Brazil, Burundi, China, Cuba, Ghana, Guyana, India, Mexico, Nigeria, Philippines, Sudan, Tanzania, Thailand, Venezuela, and Vietnam.

Out of a great number of applicants, a Selection Committee, headed by a representative of UNEP, selects the most suitable candidates according to certain fixed criteria, and with the proviso that each application bears a clear statement of support from the government concerned, as well as indications of appropriate university education and previous experiences in the field of environmental management. Priority is given to applicants who are already in a senior administrative position in their respective countries and seem likely to have an effective influence on the decision-making process after their return home.

The scientific training programme of the Course, held over a period of ten months (from October to July), comprises lectures, seminars, study tours, field-work, and laboratory exercises, in the following fields: environmental strategies, ecological fundamentals, agro-ecosystems, land- use planning and food production, animal husbandry and the environment, forest resources management and agroforestry, management of aquatic ecosystems, and environmental economics.

During study tours to other European countries, the participants have an opportunity to study in detail certain environmental issues. For example, in the course of an educational stay at the International Institute for Applied Systems Analysis (Laxenburg, Austria), the participants acquaint themselves with methods of ecological modelling and its practical use in the process of Environmental Impact Assessment (EIA).

Assessment of the participants themselves is based on examinations and the evaluation of a final paper, including its presentation at the end of the Course. The theme of the final paper is selected by the authorities of the respective countries, and is related to a main environmental problem in those countries.

The UNEP/UNESCO Postgraduate Training Course represents a unique opportunity for professionals engaged in different environmental fields to update their knowledge in order to be able to support appropriate decision-making by incorporation of environmental issues in development policy, plans, and activities. It also provides a chance to stimulate the development of conservationists' attitudes and strategies in the less-developed countries, in order to promote the rational use of their natural resources.

\author{
Walter D.S. Leal Filho \\ School of Environmental Science \\ University of Bradford \\ Bradford \\ West Yorkshire BD7 IDP \\ England, UK.
}

\section{International Dawn Chorus Day}

The sixth of these annually recurring events, which were started by the Urban Wildlife Group in 1984 in an attempt to bring together people internationally through their mutual enjoyment of a unique wildlife experience, has been scheduled for Sunday, 30 April 1989, when people throughout the world are asked to open their windows widely at dawn and listen to the chorus of birdsong. The object is not only to make people enlighteningly aware of the beauty and diversity of their natural environment, but also to impress on them the uniqueness of wildlife even in many an urban setting. Following on from the success of previous years, it is hoped that we can make this a truly international event and actually link the world in global appreciation of birdsong.

In Birmingham, the Urban Wildlife Group functions as an agency for public awareness of the enormous variety of wildlife that exists in the city, while also campaigning to prevent needless destruction of wildlife areas. In addition, urban conservation is concerned with creating new landscapes for people and habitats for wildlife. Our team of experts cover all major aspects of environmental conservation, from publicizing important issues to the practical application of landscaping techniques.

Since its inception in 1980, the Urban Wildlife Group has had great success in transforming the way in which people think about their urban surroundings, so that it is being spoken of as one of the leading urban conservation concerns in the United Kingdom.
HARVEY WiTHERS Urban Wildlife Group 131-133 Sherlock Street Birmingham B5 $6 N B$ England, UK. 